\title{
Editorial
}

\section{Cardiovascular disease and high cholesterol in old age}

Serum cholesterol is a strong predictor of coronary heart disease (CHD) in men less than 60 years old, ${ }^{1}$ and lowering cholesterol in this age group reduces CHD and total mortality. ${ }^{2}$ Is this relevant to those over 65 years? We need to know: (1) whether high cholesterol is an important risk factor for CHD in the old; (2) how long the putative beneficial effects of lowering serum cholesterol take to appear; (3) whether old people can respond to cholesterol lowering regimens as well as the young; and (4) whether cholesterol-lowering programmes in the old can reduce overall mortality. The answers to some of these points are now clear.

1) Four good studies ${ }^{3-6}$ of men and women aged up to 80 years have now confirmed that those with a total serum cholesterol in the highest quartile of the population have an approximately $50 \%$ increase in the risk of both fatal and nonfatal CHD compared with those in the lower quartiles. By contrast, no link has been found between serum cholesterol and stroke. ${ }^{7}$ This is possibly because fatal coronary artery disease appears before clinically significant cerebrovascular disease.

2) Two lines of evidence suggest that the benefit from lowering cholesterol in middle-aged men occurs quickly. An overview of 20 trials of cholesterol lowering in this age group ${ }^{8}$ showed that a $10 \%$ cholesterol reduction resulted in a $22 \%$ fall in $\mathrm{CHD}$ events in three years. In studies which used coronary angiography to measure outcome, a reduction of apolipoprotein-B by about $30 \%$ resulted in a significant improvement of angiographic appearance (and a reduction in coronary events) in just 2.5 years. $^{9}$

3) In younger subjects, significant cholesterol lowering is easily achievable with diet and HMG CoA reductase inhibitors; $\mathrm{CHD}$ incidence falls by $2-3 \%$ for every $1 \%$ reduction in cholesterol. ${ }^{8}$

The answer we now await is whether cholesterol-lowering programmes will reduce overall mortality in the elderly - these trials are under way. In the mean time it seems clear that we should give advice on smoking, ${ }^{10}$ diet $^{11}$ and exercise $^{12}$ and the finding of a very high cholesterol in an elderly patient should prompt screening of younger blood relatives. Although there is no reason to suppose that the elderly will benefit less from cholesterol lowering than 


\section{Editorial}

the young we should await more conclusive evidence before embarking on a widespread programme of screening and treatment. Some gerontologically interesting questions will still remain:

- Should those receiving treatment for raised lipids in middle age continue treatment for life?

- Do people develop hyperlipidaemia late in life, and if so are they different from those who develop it earlier?

- Are those who survive into old age with raised lipids different from those who do not?

After years of uncertainty we now know that treatment of hypertension in the old is important - the next few years will tell us whether the same is true for lipids.

$D L$ Cohen, Department of Clinical Geratology, Radcliffe Infirmary and JS Mindell, Lipid Clinic, John Radcliffe Hospital, Oxford, UK.

\section{References}

1 Martin MJ, Hulley SB, Browner WS et al. Serum cholesterol, blood pressure and mortality: implications from a cohort of 361,662 men. Lancet 1986; i: 933-36.

2 Canner PL, Berge KG, Wenger NK et al. Fifteen year mortality in Coronary Drug Project patients: long term benefit with niacin. J Am Coll Cardiol 1986; 8: 1245-55.
3 Barret-Connor E, Suarez L, Khaw K, Criqui MH, Wingard DL. Ischaemic heart disease risk factors after age 50. J Chronic Dis 1984; 37: 903-908.

4 Harris T, Cook EF, Kannel WB, Goldman L. Proportional hazards analysis of risk factors for coronary heart disease in individuals aged 65 or older. $J$ Am Geriatr Soc 1988; 36: 1023-28.

5 Benfante R, Reed W. Is elevated serum cholesterol level a risk factor for coronary heart disease in the elderly? JAMA 1990; 263: 393-96.

6 Rubin SM, Sidney S, Black DM et al. High blood cholesterol in elderly men and the excess risk for coronary heart disease. Ann Intern Med 1990; 113: 916-20.

7 Chen Z-M, Collins R, Peto R. Serum cholesterol levels and stroke mortality. $N$ Engl J Med 1989; 321: 1339.

8 Peto R, Yusuf S, Collins R. Cholesterol-lowering trial results in their epidemiologic context. Circulation 1985; 72 (suppl 3): III-451.

9 Brown G, Albers JJ, Fisher LD et al. Regression of coronary artery disease as a result of intensive lipidlowering therapy in men with high levels of apolipoprotein-B. N Engl J Med 1990; 323: 1289-98.

10 Friedman GD, Petitti DB, Bawol RD, Sieglaub AB. Mortality in cigarette smokers and quitters: effect of base-line differences. $N$ Engl J Med 1981; 304: 140710.

11 National Advisory Committee on Nutrition Education. Proposals for nutritional guidelines for health education in Britain. London: Health Education Council, 1983.

12 Blumenthal JA, Emery CF, Madden DJ et al. Cardiovascular and behavioural effects of aerobic exercise training in healthy older men and women. $J$ Gerontol 1989; 44: M147-57. 